\title{
The Effects of Parent Training on Parenting Stress and Sense of Competence
}

\author{
SUSAN PISTERMAN, PHILIP FIRESTONE, PATRICK MCGRATH, \\ JOHN T. GOODMAN, IKUKO WEBSTER, RISA MALLORY, and BEA \\ GOFFIN, Children's Hospital of Eastern Ontario, Ottawa, Canada
}

\begin{abstract}
The effects of behavioural parent training groups on parenting stress and sense of competence were investigated. Subjects were 91 families of ADDH preschoolers who participated in one of two randomized control studies that demonstrated the efficacy of group parent training in the amelioration of child noncompliance. Compared to parents awaiting treatment, parents who completed training reported significant improvements on the Parenting Stress Index (PSI) Parent Domain, and both Skills and Valuing subscales of the Parenting Sense of Competence Scale (PSCS) immediately after treatment and three months later. Intercorrelations among the self-report measures as well as their relationships with other variables were examined. Significant correlations were found between improvements on the PSCS Skills and Valuing subscales. Improvement on the PSCS Valuing subscale was also associated with decreases in the PSI Parent Domain. Improvements on the PSI Child Domain and PSCS Valuing subscale were significantly correlated with parents' perceptions of improvement in their children's behaviour. No significant correlations were found between self-report improvements and observed changes in parent or child behaviour or parental compliance to treatment. The results indicated that group parent training had a positive impact on parenting stress and sense of competence. These changes were independent of improvements in actual parent and child behaviour assessed in the clinic.
\end{abstract}

\section{Résumé}

Les effets sur le stress et le sentiment de compétence des parents que peuvent avoir les formations de groupes agissant sur le comportement parental sont étudiés dans le présent article. Les sujets, quatre-vingt-onze familles d'enfants ADDH d'âge préscolaire, ont participé, au hasard, à l'une des deux études de contrôle qui cherchaient à démontrer l'efficacité de ces groupes de formation sur l'amélioration de la désobéissance chez les enfants. Comparés aux parents n'ayant pas encore reçu cette formation, les parents ayant complété leur formation ont enregistré des améliorations significatives sur l'Index de stress parental (PSI) - côté parents, et sur les sous-échelles des techniques et des valeurs de l'indice du sentiment de compétence parental (PSCS) dès la fin de la 
période de formation et trois mois plus tard. Les corrélations entre les mesures effectuées lors de l'auto-évaluation ainsi que leurs relations avec les autres variables ont également été étudiées. On a observé des rapports significatifs entre les améliorations notées à la sous-échelle des techniques et à celle des valeurs du PSCS. L'amélioration notée à la sous-échelle des valeurs a été également associée à la diminution du stress parental - côté parents évalué par le PSI. Les améliorations observées au PSI - côté enfants et à la souséchelle des valeurs ont pu être directement reliées à la perception qu'avaient les parents des changements positifs dans le comportement de leur enfant. Cependant, on n'a pas observé de rapport significatif entre l'amélioration notée dans les auto-évaluations et les changements observés dans le comportement des parents ou de l'enfant ou dans la participation des parents au traitement. Les résultats ont révélé que les groupes de formation des parents ont un effet positif sur le stress et le sentiment de compétence des parents. Ces changements étaient indépendants des améliorations notées dans les comportements actuels du parent et de l'enfant tels qu'évalués à la clinique.

Increasing recognition of the systemic nature of family functioning has led to investigations of bi-directional and transactional influences in the etiology and treatment of child behaviour problems; complex theories have been proposed to account for the interplay between environmental, parental and child factors (cf. Belsky, 1984; Blechman, Tryon, Ruff, \& McEnroe, 1989; Dodge 1990; Dumas, 1984; Hammen, Burge \& Stansbury, 1990: Johnston, 1988; Minuchin, 1974).

Consistent with a systems approach to family dysfunction, Mash and Johnston (1990) have illustrated how the relative roles of parent and child characteristics can differentially impact on parent-child stress depending upon the clinical context. For example, research findings suggest that whereas parental factors may play a critical role in families with physically abused children, child characteristics appear to be more instrumental in parent-child stress in families of hyperactive children.

The recalcitrant and chronic nature of attention deficit hyperactivity disorder ${ }^{1}$ appears to challenge parents' sense of competence and functions as a potent source of stress related to the parenting role. Loyd and Abidin (1985) have reported that amongst families with children experiencing chronic physical or psychological disorders, parents of behaviour-disordered and hyperactive youngsters report the highest levels of stress. Mash and Johnston

'The diagnostic terms, attention deficit hyperactivity disorder, ADDH, and hyperactivity refer to the childhood disorder characterized by inattention, impulsivity, and overactivity. Attention deficit hyperactivity disorder reflects current diagnostic criteria; ADDH reflects the diagnostic criteria used to select the samples studied. Hyperactivity is used as a generic term. 
(1983) have also found that sense of parenting competence was lower in parents of older hyperactive children than in those with younger hyperactive offspring despite the more problematic behaviour in the younger group. They speculated that this developmental trend reflected parental response to a history of unsuccessful attempts to control difficult and unpredictable child behaviour.

The impact of the hyperactive child's behaviour on parent behaviour has also been illustrated in studies assessing the effects of stimulant medication. As hyperactive and noncompliant behaviour improves in the child following use of methylphenidate, maternal behaviour becomes less directive and more positive (Barkley \& Cunningham, 1979; Barkley, Karlsson, Pollard \& Murphy, 1985). Similar changes have been obtained in parent-mediated interventions. Pisterman and her colleagues (1989, 1990) evaluated the effects of group parent training programs on the interactions of parents and their hyperactive preschoolers. They found that treated parents became less directive and more positive with their children and that the percentage of child compliance to parental commands also improved compared to an untreated group. Given the positive impact of these parent programs on parent and child behaviour and the focus on parent skills and knowledge, it was hypothesized that the therapeutic benefits of parent programs should extend to parenting stress and sense of competence. The relationships between outcome measures were also investigated in an attempt to understand the ways in which these programs function therapeutically.

\section{Method}

SUBJECTS

Subjects were 91 families of clinically-diagnosed preschoolers who completed participation in one of two studies evaluating group parent training programs. The first study (Pisterman, McGrath, Firestone, Goodman, Webster, \& Mallory, 1989) focused on the amelioration of child noncompliance; the second (Pisterman, McGrath, Firestone, Goodman, Webster, Mallory, \& Goffin, 1990) addressed both problems of noncompliance and short attention span. Subjects met the following inclusion criteria:

1) Diagnostic and Statistical Manual of Mental Disorders-III (DSM-III: American Psychiatric Association, 1980) criteria for a diagnosis of attention deficit disorder with hyperactivity (ADDH) were met by each child. In the first study this was determined through a structured screening interview with the primary care, i.e. target, parent. Although no independent reliability checks were performed, consultation with the supervising PhD psychologist was used in cases of guestionable diagnosis.

In the second study diagnosis was based on ratings by either parent or teacher on the SNAP checklist (Pelham \& Bender, 1982), a rating scale derived from the specific DSM-III items for attention deficit disorder with hyperactivity. 
TABLE I

Characteristics of the Sample at Pretreatment: Descriptive Statistics and Results of Study $\times$ Group Analysis of Variance and Chi-Square Tests

\begin{tabular}{|c|c|c|c|c|c|c|c|}
\hline \multirow[b]{2}{*}{ Variable } & & \multicolumn{2}{|c|}{ First Study } & \multicolumn{2}{|c|}{ Second Study } & \multirow{2}{*}{$\begin{array}{l}\text { Study } \\
F(1,89)\end{array}$} & \multirow{2}{*}{$\begin{array}{l}\text { Group } \\
F(1,89)\end{array}$} \\
\hline & & Treament & Control & Treatment & Control & & \\
\hline Sample size & & 23 & 23 & 23 & 22 & & \\
\hline \multicolumn{8}{|l|}{ Child } \\
\hline \multicolumn{8}{|c|}{ Age (months) } \\
\hline $\begin{array}{l}M \\
S D\end{array}$ & $\begin{array}{l}50.5 \\
(9.6)\end{array}$ & & $\begin{array}{l}49.8 \\
(9.1)\end{array}$ & $\begin{array}{l}46.8 \\
(7.4)\end{array}$ & $\begin{array}{c}52.4 \\
(10.1)\end{array}$ & 0.09 & 1.67 \\
\hline \multicolumn{8}{|l|}{ PPVT $^{a}$} \\
\hline $\begin{array}{l}M \\
S D\end{array}$ & $\begin{array}{l}98.8 \\
(0.4)\end{array}$ & & $\begin{array}{r}100.5 \\
(0.4)\end{array}$ & $\begin{array}{c}100.3 \\
(0.6)\end{array}$ & $\begin{array}{c}106.5 \\
(0.6)\end{array}$ & 1.83 & 200 \\
\hline \multicolumn{8}{|c|}{$\begin{array}{l}\text { Conners Hyperactivity } \\
\text { Index }\end{array}$} \\
\hline $\begin{array}{l}M \\
S D\end{array}$ & $\begin{array}{l}1.9 \\
(0.4)\end{array}$ & & $\begin{array}{c}2.1 \\
(0.4)\end{array}$ & $\begin{array}{c}1.8 \\
(0.6)\end{array}$ & 2.0 & 0.56 & 2.89 \\
\hline \multicolumn{8}{|c|}{$\begin{array}{l}\text { Conners Conduct } \\
\text { Problem }^{b}\end{array}$} \\
\hline $\begin{array}{l}M \\
S D\end{array}$ & $\begin{array}{c}1.2 \\
(0.9)\end{array}$ & & $\begin{array}{c}1.5 \\
(0.9)\end{array}$ & $\begin{array}{c}1.2 \\
(0.8)\end{array}$ & $\begin{array}{c}1.4 \\
(0.8)\end{array}$ & 0.11 & 4,40 \\
\hline $\begin{array}{l}\text { Conners } \\
M \\
S D\end{array}$ & $\begin{array}{c}0.9 \\
(10.0)\end{array}$ & & $\begin{array}{c}1.0 \\
(9.2)\end{array}$ & $\begin{array}{c}0.9 \\
(10.5)\end{array}$ & $\begin{array}{c}1.1 \\
(128)\end{array}$ & 0.04 & 0.84 \\
\hline \multicolumn{8}{|c|}{$\begin{array}{l}\text { Percentage of } \\
\text { Combilance }^{c}\end{array}$} \\
\hline $\begin{array}{l}M \\
S D\end{array}$ & $\begin{array}{r}39.7 \\
(10.0)\end{array}$ & & $\begin{array}{l}40.4 \\
(9.2)\end{array}$ & $\begin{array}{c}28.7 \\
(10.5)\end{array}$ & $\begin{array}{c}34.7 \\
(128)\end{array}$ & ${ }^{* 4} 13.91$ & 2.23 \\
\hline \multicolumn{8}{|c|}{ Level of education ${ }^{d}$} \\
\hline $\begin{array}{l}M \\
S D\end{array}$ & $\begin{array}{l}13.9 \\
(2.2)\end{array}$ & & $\begin{array}{l}13.4 \\
(2.5)\end{array}$ & $\begin{array}{l}13.3 \\
(2.1)\end{array}$ & $\begin{array}{l}13.4 \\
(2.6)\end{array}$ & 0.40 & 0.14 \\
\hline
\end{tabular}

Continued ... 


\begin{tabular}{|c|c|c|c|c|c|c|}
\hline \multirow[b]{2}{*}{ Variable } & \multicolumn{2}{|c|}{ First Study } & \multicolumn{2}{|c|}{ Second Study } & \multirow{2}{*}{$\begin{array}{l}\text { Study } \\
F(1,89)\end{array}$} & \multirow{2}{*}{$\begin{array}{l}\text { Group } \\
F(1,89)\end{array}$} \\
\hline & Treament & Control & Treatment & Control & & \\
\hline \multicolumn{7}{|l|}{ Percentage positive $^{e}$} \\
\hline$S D$ & $\begin{array}{l}26.4 \\
26.4\end{array}$ & $\begin{array}{l}27.2 \\
27.2\end{array}$ & $\begin{array}{l}18.4 \\
18.4\end{array}$ & $\begin{array}{l}225 \\
225\end{array}$ & $\begin{array}{r}0.40 \\
* 13.88\end{array}$ & $\begin{array}{l}0.14 \\
2.15\end{array}$ \\
\hline \multicolumn{7}{|l|}{ Child } \\
\hline \multicolumn{7}{|l|}{ Gender } \\
\hline Male & 18 & 19 & 22 & 19 & & \\
\hline Female & 5 & 4 & 1 & 3 & 2.12 & 0.12 \\
\hline \multicolumn{7}{|c|}{ Medication for ADHD } \\
\hline Off & 21 & 20 & 21 & 21 & & \\
\hline On & 2 & 3 & 2 & 1 & 0.50 & 0.00 \\
\hline \multicolumn{7}{|l|}{ Family Composition } \\
\hline Single parent & 4 & 3 & 2 & 5 & & \\
\hline Two parent & 19 & 20 & 21 & 17 & 0.00 & 0.39 \\
\hline
\end{tabular}

Note. $N=$ Study $\times$ Group interaction was not significant for any of the analyses of variance.

"Standard score equivalent for Peabody Picture Vocabulary Test-Revised. 'Rated by target parent. "Based on compliance task segment of behavioural assessment; relative to frequency of parental commands. "Years of schooling from Grade 1 on. "Relative to total behaviours coded; based on the entire session of behavioural assessment.

${ }^{*} p<.05$

${ }^{* *} p<.001$ 
In both studies concurrent diagnoses were not made, but information about co-occurring problems was obtained through the Conners Parent Rating Scale (Conners, 1989) completed by the target parent. As indicated in Table 1, the children in both studies were rated as having significant conduct problems, the mean for the overall sample being approximately 2 standard deviations above the age mean on the Conduct Factor (Conners, 1989). A significant difference was found between control and treatment groups across the two studies with conduct problems rated as more severe in the control group. Problems of compliance were evident in both groups; percentage compliance was dramatically lower than the $60 \%$ clinical cut-off standardly used in the compliance literature (Forehand \& McMahon, 1981) and percentage compliance was significantly lower for families in Study 2 compared to Study 1. Ratings on the Conner's Anxiety Factor were not, overall, in the clinical range.

2) In Study 1 a parent or teacher rating of 1 standard deviation above the age and gender mean on the Hyperactivity Index of the Revised Conners Rating Scales (Conners, 1989) was required. In Study 2 a rating of 1.5 standard deviations above the age and gender means was used. The actual ratings by the primary care parent in both studies were almost identical. The group means were over 2 standard deviations above normed age and gender means (Table 1 ).

3) A standard score equivalent $=80$ on the Peabody Picture Vocabulary Test (PPVT) (Dunn \& Dunn, 1981) was used for unilingual English children in both studies. For bilingual children the cut-off was 72 in Study 1 and 76 in Study 2.

4) In both studies children had to be between 3 and 6 years old and not yet attending Grade 1.

5) In Study 1, the percentage of child compliance to total parental commands had to be $<60 \%$ at pretreatment in a standardized compliance task. In Study 2 the behavioural criterion, mean time on task in a standardized parent-supervised attention task at pretreatment, was $<163 \mathrm{sec}$. This cut-off represents 2 standard deviations above the mean of $50 \%$ of the study children meeting the DSM-III criteria for ADDH.

6) Hyperactivity medication of the 8 children on medication had to be constant throughout participation.

The drop-out rate was $8 \%$ in Study 1 and $21 \%$ in Study 2 with no differences between the groups. The differential drop-out rates may be indicative of the more dysfunctional nature of the subjects in Study 2 (see Table 1) as indicated by lower rates of percentage compliance and of percentage of positive parental behaviour at pretreatment. The samples were comparable on all other measures at pretreatment.

\section{DESIGN}

Families of eligible children were randomly assigned to an immediate 
treatment group (experimental group) or a delayed treatment group (control group).

Behavioural assessments were conducted and parent ratings of child behaviour and parent self-report measures were obtained at pretreatment, posttreatment and at 3-month follow-up for all families. Parents were queried at each assessment whether other parent training had been received during that period and none was reported.

Parents in the control group were told that normal developmental changes needed to be monitored to determine what effects the program had beyond maturational changes. Following the 3-month follow-up assessment, families in the control group received the same treatment program.

\section{ASSESSMENT}

Eligibility was determined through a screening assessment consisting of three sessions attended by the target parent and child. In all but 3 families the target parent was the mother. In the first, a comprehensive semi-structured diagnostic interview was conducted. Non-target parents typically attended. In the second session the child was administered the PPVT while the parent completed child behaviour and self-report questionnaires and consent forms. The behavioural assessment was conducted in the third session. All assessments were conducted by an MA-level therapist and took place in a room equipped with a one-way mirror.

In the first study the behavioural assessment was comprised of 10 minutes of free play in which the target parent was instructed to interact with the child as if at home. This was followed by 20 minutes in which the parent was given a list of 15 instructions to be issued to the child (adapted from Barkley, 1981). After a short break the parent supervised the child during two activities. First the child had to copy a series of increasingly more complex designs using plastic shapes (10 $\mathrm{min}$ ); then the child had to complete 4 puzzles (10 min). The parent was instructed to assist as desired. The session concluded with 10 more minutes of free play.

In the second study the behavioural assessment also began with 10 minutes of free play. However, in keeping with the focus on child attention, the parent was instructed to let the child play independently. This procedure allowed the measurement of independent sustained play activity. The compliance task used in Study 1 followed. After a short break, the parent was instructed to assist the child as desired in copying a series of increasingly difficult dot-to-dot designs (10 $\mathrm{min}$ ). Following this the therapist instructed the child on a cancellation task and requested that the child complete the task independently while the parent read a magazine (10 min). The assessment concluded with 10 more minutes of independent free play.

Parent-child interactions were coded from videotape following Forehand and McMahon's procedure (1981) by a rater uninformed about group assignment. A second rater coded one eighth of the tapes. In both studies 
coded parent behaviours included commands (alpha or appropriate commands and beta or inappropriate commands), questions, positive comments, and negative comments. Reinforcement of child compliance was also recorded in Study 1 . Child behaviours coded in both studies included compliance, noncompliance and on-task behaviour. In Study 1 a general category of inappropriate behaviour was measured; in Study 2 this was restricted to aggressive behaviour. Kappas ranged from .614 for inappropriate child behaviour in Study 1 to .946 for on-task behaviour.

\section{INTERVENTION}

The parent training program in each study was conducted in group format (5 families per group) and involved 12 weekly sessions. Both parents of two-parent families were encouraged to attend; attendance by the target parent was required. Each program began with information covering the diagnostic, etiological, familial, developmental and treatment issues related to $A D D H$. These were followed by instructional units involving role-playing, modeling by the therapist, and homework assignments. Parents were provided with general reading material and specially-developed manuals.

In Study $I$ compliance training involved management techniques to improve parent-child interaction and child compliance (Barkley, 1981; Eyberg \& Robinson, 1982; Forehand \& McMahon, 1981; Hanf, 1969). Parents were taught how to issue appropriate commands while attending to appropriate behaviours, and implement time-out procedures. Afterwards each target parent and child attended the clinic and engaged in standardized tasks. The parent was provided with videotape feedback and individual instruction. At comparable points in time each control parent and child also attended the clinic and participated in the same tasks. However no feedback was given, but general information about the child's behaviour was solicited.

In Study 2 the compliance program from Study 1 was essentially the same but condensed. The first clinic session took place after instruction in time-out for noncompliance. This was followed by attention training which incorporated the skills taught in compliance training. Parents were provided with a baseline of on-task behaviour based on the individual behavioural assessments at pretreatment. Parents were instructed initially to reinforce their children's on-task behaviour every time their child reached criterion based on his/her baseline rate. Whenever the child went off-task, the parent was instructed to issue a "re-focusing" command, i.e. instructing the child to resume the task. Failure of the child to resume the task was considered noncompliance and parents were instructed to implement the contingency management strategies previously taught for noncompliance. As the child's attention span increased, parents extended reinforcement to other aspects of performance such as neatness and accuracy. Parents and children attended another clinic visit for videotape feedback and individual instruction following the completion of attention training. In the control group parent 
and child engaged in the same tasks given to treatment families, but no feedback nor instruction was provided.

\section{OUTCOME MEASURES}

Outcome measures were taken from the three forms of assessment: observational, child behaviour ratings and parent self-report. For the purpose of the present report two major variables derived from the behavioural assessments were included. The first, percentage of child compliance relative to parental commands was a dyadic measure of parent-child interaction around parental request for compliance in a standardized compliance task. This measure served as a major outcome variable in both studies. The second behavioural outcome measure was percentage positive. This variable measured the percentage of all parental coded behaviour that was positive and served as an index of how positive the parent's overall style of interaction was with the child. Significant treatment effects had been obtained on both these measures at posttreatment and 3-month follow-up in both studies.

The child behaviour rating scales completed by target parents included the Conners' Parent Rating Scales - 48 (Conners, 1989), the Home Situations Questionnaire (Barkley, 1981) and Kendall and Wilcox's (1979) Self-Control Rating Scale modified for preschoolers (Pisterman et al., 1989). A composite child rating score was obtained by summing the $z$ scores of the Conners' Hyperactivity Index, the Conners' Conduct Problem Factor, the sum of severity ratings on the Home Situations Questionnaire and the Self-Control Rating Scale.

Parenting sense of competence was measured by Mash and Johnston's (1983) version of Gibaud-Wallston and Wandersman's (1978) Parenting Sense of Competence Scale (PSCS). This parental self-report questionnaire yields two subscales. The Skills subscale reflects parental self-perceptions of skill and knowledge regarding parental functions. Representative items include: Being a parent is manageable and any problems are easily solved, and I honestly believe I have all the skills necessary to be a good mother/father to my child. The Valuing subscale measures feelings of satisfaction, frustration, and interest associated with parenting. Items include: Even though being a parent would be rewarding, I am frustrated now while my child is at his/her present age and, My talents and interests are in other areas, not in being a parent. Adequate psychometric properties have been reported by the original authors (Gibaud-Wallston \& Wandersman, 1978) and more recently by Johnston and Mash (1989).

The Parenting Stress Index (PSI) was used to assess self-reported stress related to parenting. Extensive research has been conducted demonstrating sound psychometric properties (Loyd \& Abidin, 1985). The Child and Parent Domain subscales were used. The Child Domain is comprised of 6 scales relating to child characteristics of adaptability, acceptability, demandingness, mood, distractibility/hyperactivity and reinforcing value to the parent. The 
TABLE 2

Descriptive Statistics and Group $\times$ Assessment Interactions for Parenting Sense of Competence Scale (PSCS) Subscale Scores and Parenting Stress Index (PSI) Domain Scores

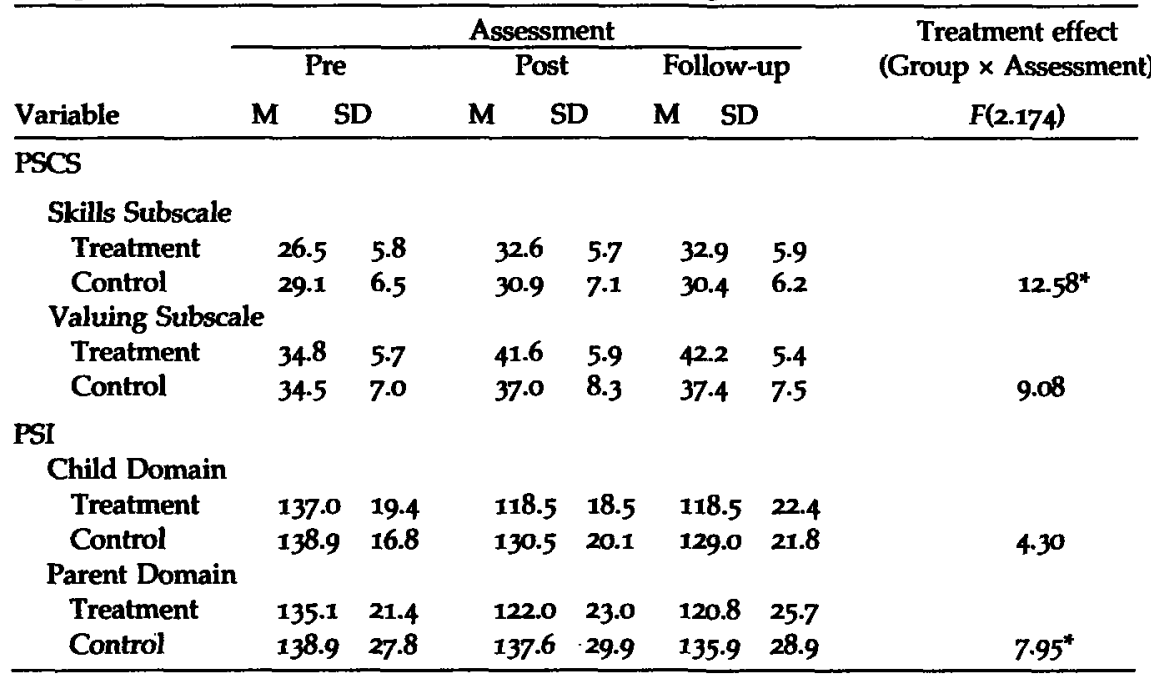

Note. Multivariate analysis of variance results; Group $\times$ Assessment interaction $\mathbf{F}(8,342)=4.23$.

$\mathbf{p}<.001$.

${ }^{*} \mathbf{p}<.001$.

Parent Domain is composed of 7 individual scales which tap general affective and physical functioning as well as subjective feelings directly related to parenting. The subscales tap depression, attachment, restriction of role, sense of competence, social isolation, relationship with spouse and physical health.

In addition, parental compliance to treatment, a process variable, was obtained by averaging the percentage of sessions attended and homework assignments completed by treatment group families.

\section{Results \\ DATA ANALYSIS}

Initial multivariate analyses of variance (MANOVAs) which included "Study" as an independent factor yielded consistent results across the two studies; consequently the findings reported here are based on analyses of the combined samples. A series of $2 \times 3$ (Group $\times$ Assessment) MANOVAs was carried out on 3 sets of parent self-report measures: 1 . the two Parenting Sense of Competence subscales and the two Parenting Stress Index domain scores, 2. the six PSI Child Domain subscale scores, and 3. the seven PSI Parent Domain subscale scores. Treatment effects were reflected in significant Group $\times$ Assessment interactions. Univariate analyses of variance (ANOVAs) were then conducted on each set of measures that yielded a significant treatment effect. As well, post hoc between-assessment comparisons for the 
two groups were performed using Spjotvoll and Stoline's modification of Tukey's HSD test to control for experiment-wise error for multiple tests (Kirk, 1982). A significance level of $p<.01$ (2-tailed) was used for all analyses in consideration of the number of analyses performed.

A Pearson product-moment correlation matrix for the treatment group families was also obtained in order to examine the relationships between preto posttreatment changes in the four primary self-report variables and other outcome and process variables: These included parents' global perceptions of child behaviour change, changes in dyadic interaction around compliance and parental style of interaction. Parental compliance to treatment was included to determine if there was a relationship between parental commitment to and involvement in treatment and changes in feelings of stress and competence.

\section{PSCS SUBSCALE AND PSI DOMAIN SCORES}

The means, standard deviations, and results of the MANOVA and ANOVAs for the four primary self-report measures are presented in Table 2. The MANOVA yielded a significant Group $\times$ Assessment interaction and subsequent ANOVAs revealed significant treatment effects on three of the four variables, PSCS Skills and Valuing, and PSI Parent Domain.

Post-hoc analyses (Tukey's HSD Test; Kirk, 1982) revealed that for the PSCS Skills Subscale score, the treatment effect reflected a significant increase in sense of competence from pretreatment to posttreatment $\left(q^{\prime \prime} T^{\prime \prime 2}=11.13\right.$, $d f=174, p<.01)$ and 3 -month follow-up $\left(q^{\prime \prime} T^{\prime \prime}=11.57, d f=174, p<.01\right)$ in the treatment group, as opposed to no significant changes across assessments in the control group.

For the PSCS Valuing Subscale score, the treatment effect reflected a significant increase in positive feelings about parenting at posttreatment ( $q$ " $T$ " $=11.42, d f=174, p<.01)$ and at follow-up $\left(q^{\prime \prime} T^{\prime \prime}=<12.33, d f=174, p<.01\right)$ in the treatment group. In contrast the control group showed much smaller increments, although the change from pre- to follow-up was significant ( $q$ " $T$ " $=4.97, d f=174, p<.01$ ).

Based on Johnston and Mash's (1989) norms from a neighbourhood sample of mothers of 4 to 6 year olds, treated parents improved, on average, I standard deviation from pre- to post- and follow-up assessments on both Skills and Valuing subscales. Of interest, pretreatment levels were within 1 standard deviation above and below the normed means for the Skills and Valuing subscales, respectively.

For the PSI Child Domain score, the Group $\times$ Assessment interaction only

${ }^{2} \mathrm{q}^{\prime \prime} \mathrm{T}$ " $=$ test statistic for Spjotvoll and Stoline's modification of Tukey's HSD test (Kirk, 1982), $p$ (number of means) $=6, d f$ (for the error term) $=174$. 
approached the significance level $(p=.015)$. Paired comparisons revealed that the treatment group mean was significantly lower at posttreatment $\left(q^{\prime \prime} \mathrm{T}^{\prime \prime}=-\right.$ 9.92, $d f=174, p<.01)$ and at follow-up ( $\left(\mathrm{q}^{\prime \prime} \mathrm{T}^{\prime \prime}=-9.91, d f=174, p<.01\right)$ as compared with pretreatment. Percentile ranks changed from the 97 th percentile at pre- to the 87th at post- and follow-up (Abidin, 1983). However, the control group mean also showed a progressive decline that reached the significance level at follow-up $(q " T "=-5.34, d f=174, p<.01)$. However, percentile ranks changed negligibly from the 98 th percentile at pre- to the 95th at post- and follow-up. Thus over time, parents felt less stress regarding characteristics of their children, with treated parents reporting greater declines. Stress levels, however, remained high for both groups.

For the PSI Parent Domain score, a much lower level of personal stress was reported by treatment group parents at posttreatment $\left(q^{\prime \prime} \mathrm{T}^{\prime \prime}=-7.70, \mathrm{df}\right.$ $=174, p<.01)$ and at follow-up $\left(q^{\prime \prime} \mathrm{T}^{\prime \prime}=-8.38, d f=174, p<.01\right)$ as compared with pretreatment. Treated parents reported a decrease in stress from the 73rd percentile at pretreatment to the 53rd percentile at post- and follow-up assessments. In contrast, parents in the control group reported virtually no change at postassessment or follow-up from their pretreatment level at the 78th percentile (Abidin, 1983).

\section{PSI SUBSCALE SCORES}

The MANOVA conducted on the six subscale scores of the PSI Child Domain failed to yield a significant treatment effect.

The means, standard deviations and results of the MANOVAs and ANOVAs for the seven subscale scores of PSI Parent Domain are presented in Table 3. The MANOVA revealed a significant Group $\times$ Assessment interaction, and subsequent ANOVAs showed that two of the seven subscales, Depression and Sense of Competence, detected a significant treatment effect.

On the Depression subscale, the treatment group mean declined significantly from pre- to posttreatment ( $\left.q^{\prime \prime} \mathrm{T}^{\prime \prime}=-8.05, \mathrm{df}=174, p<.01\right)$, and also from pre-treatment to follow-up $\left(q^{\prime \prime} \mathrm{T}^{\prime \prime}=-8.41, d f=174, p<.01\right)$. This change represented a drop from the 74th percentile at pretreatment to the 43rd percentile at postassessment (Abidin 1983). This improvement was maintained at follow-up. In contrast, the control group pretreatment mean, representing the 73 rd percentile, remained virtually unchanged across assessments.

A similar pattern of change was found on the Sense of Competence subscale. The treatment group mean declined significantly from pre- to posttreatment $\left(q^{\prime \prime} \mathrm{T}^{\prime \prime}=-8.43, d f=174, p<.01\right)$ and also from pretreatment to follow-up ( $q$ " $\left.T^{\prime \prime}=-9.80, d f=174, p<.01\right)$. Treated parents went from the 87th percentile at pretreatment to the 65 th at post-assessment (Abidin, 1983). Although a small gradual decline across assessments was observed in the control group mean, these changes were not statistically significant and remained within the 8 oth percentile range. Thus, treated parents felt less 
TABLE 3

Descriptive Statistics and Group Assessment Interactions for Parent Domain Subscale Scores of Parenting Stress Index

\begin{tabular}{|c|c|c|c|c|c|c|c|}
\hline \multirow[b]{3}{*}{ Variable } & \multicolumn{6}{|c|}{ Assessment } & \multirow{3}{*}{$\begin{array}{c}\text { Treatment effect } \\
\text { (Group } \times \text { Assessmen } \\
\text { interaction } \\
F(\mathbf{2 , 1 7 4 )} \\
\end{array}$} \\
\hline & \multicolumn{2}{|c|}{ Pre } & \multicolumn{2}{|c|}{ Post } & \multicolumn{2}{|c|}{ Follow-up } & \\
\hline & $\mathbf{M}$ & $\mathrm{D}$ & $\mathbf{M}$ & $\mathbf{D}$ & $\mathbf{M}$ & & \\
\hline \multicolumn{8}{|l|}{ Depression } \\
\hline Treatment & 22.7 & 4.8 & 18.8 & 5.4 & 18.6 & 4.8 & \\
\hline Control & 22.6 & 6.5 & 22.6 & 6.9 & 22.4 & 6.7 & $10.83^{*}$ \\
\hline \multicolumn{8}{|l|}{ Attachment } \\
\hline Treatment & 13.8 & 3.5 & 12.8 & 3.6 & 12.8 & 3.9 & \\
\hline Control & 14.2 & 3.4 & 14.1 & 4.0 & 14.3 & 3.8 & 1.31 \\
\hline \multicolumn{8}{|c|}{ Restriction of Role } \\
\hline Treatment & 18.9 & 5.3 & $17 \cdot 3$ & 5.1 & 17.1 & 5.3 & \\
\hline Control & 20.4 & 6.1 & 20.0 & 6.6 & 19.6 & 5.6 & 1.27 \\
\hline \multicolumn{8}{|c|}{ Sense of Competence } \\
\hline Treatment & 36.0 & 6.3 & 31.2 & 5.8 & 30.5 & 6.3 & \\
\hline Control & 35.2 & 6.9 & 34.3 & 6.8 & 33.8 & $7 \cdot 5$ & 8.54* \\
\hline \multicolumn{8}{|l|}{ Social Isolation } \\
\hline Treatment & 13.6 & 4.0 & 12.7 & 4.4 & 12.5 & 4.4 & \\
\hline Control & 13.3 & 4.2 & 13.2 & 4.4 & 13.7 & 4.5 & 3.06 \\
\hline \multicolumn{8}{|c|}{$\begin{array}{l}\text { Relationship with } \\
\text { Spouse }\end{array}$} \\
\hline Treatment & 17.5 & 4.6 & 17.5 & 4.8 & 17.6 & 5.3 & \\
\hline Control & 19.6 & 5.6 & 19.7 & 5.3 & 19.3 & 4.9 & 51 \\
\hline Parent Health & & & & & & & \\
\hline Treatment & 12.5 & 3.1 & 11.7 & 3.4 & 11.8 & 3.4 & \\
\hline Control & 13.4 & 4.0 & 13.7 & 3.6 & 12.8 & 3.7 & 1.92 \\
\hline
\end{tabular}

Note: Multivariate analysis of variance results; Group Assessment $x$ interaction $\mathrm{F}(14,336)=2.33$.

$p<.01$.

${ }^{*} \mathrm{p}<.001$.

depressed and discouraged after treatment and at 3-month follow-up and at the same time felt better about their parenting competence. The improvements in percentile ranks suggested a normalization of stress levels.

\section{SELF-REPORT CHANGE SCORES AND THEIR RELATIONSHIPS WTTH OTHER MEASURES}

Table 4 contains a correlation matrix for the treatment group families relating change scores (post-treatment - pre-treatment) in the four primary self-report measures and changes in other selected outcome and process variables.

The analysis of changes amongst the self-report measures yielded a significant positive correlation between PSCS Skills and Valuing change scores and a significant negative correlation between PSCS Valuing and PSI Parent Domain change scores. These findings suggest a relationship between positive changes in how competent parents perceived themselves and how 
TABLE 4

Correlation Matrix for Treatment Group Families Relating Pre- to Posttreatment Change Scores of Self-Report Measures, and Other Outcome Change and Process Variables

\begin{tabular}{|c|c|c|c|c|c|c|c|}
\hline Variable & 2 & 3 & 4 & 5 & 6 & 7 & 8 \\
\hline 1. PSCS Skills & .48 & ${ }^{*} .01$ & -.35 & -.17 & -.22 & -.15 & .21 \\
\hline 2. Valuing & 一 & -.35 & $-.51^{*}$ & $-.45^{*}$ & -.25 & -.00 & .16 \\
\hline 3. PSI Child Domain & & - & .35 & $.59^{* 4}$ & .02 & -.16 & -.01 \\
\hline 4. Parent Domain & & & - & .29 & .31 & -.02 & -.17 \\
\hline 5. Composite child & & & & & & & \\
\hline behaviour rating & & & & - & .04 & -.17 & -.13 \\
\hline 6. Percentage of child & & & & & & & \\
\hline compliance $^{\mathbf{b}}$ & & & & & - & .37 & .04 \\
\hline 7. Percentage of parent & & & & & & & \\
\hline positives $^{c}$ & & & & & & 一 & .10 \\
\hline $\begin{array}{l}\text { 8. Parental compliance to } \\
\text { treatment }^{\mathbf{d}}\end{array}$ & & & & & & & - \\
\hline
\end{tabular}

Note. Variables 1 to 7 are change scores (posttreatment - pretreatment).

'Based on the sum of $z$ scores for Conners' Hyperactivity Index, Conners' Conduct Problem Factor Score, Home Situations Questionnaire sum of Severity, and Self-Control Rating Scale Score. 'Based on $z$ score for percentage of child compliance relative to total parental commands to compliance task of behavioural assessments. 'Based on $z$ score for percentage of parent positives relative to total parent behaviours in the entire behavioural assessment session. ${ }^{\mathrm{d}}$ Obtained by averaging percentage sessions attended, and percentage of homework completed.

${ }^{*} p<$.01. ${ }^{* *} p<.001(N=46,2$-tailed $)$.

good they felt about parenting. These improvements in parents' feelings were also associated with declines in personal stress.

Changes in the composite child behaviour ratings were significantly correlated with PSCS Valuing and PSI Child Domain change scores. Decreases in parents' perceptions of child behaviour problems were associated with increased satisfaction with parenting and decreased stress related to characteristics of the child.

No significant correlations were found between the two behavioural measures nor between behavioural measures and child ratings or parent self-report. As well, there was no significant correlation between parental compliance to treatment and any of the other measures.

\section{Discussion}

The results of this study indicated that group parent training yielded benefits beyond changes in parent and child behaviour. Compared to parents awaiting treatment, parents who had participated in the programs reported less parenting stress and increased sense of competence following treatment and three months later. Indeed, posttreatment self-reports reflected functioning well within normal ranges.

These changes in parent stress and sense of competence were independent of improvements in actual parent and child behaviour as assessed in the 
clinical setting. However, increased parenting satisfaction and interest, and reduced stress related to child characteristics were associated with parents' perceptions of improved child behaviour.

Parents who received treatment reported positive changes in both affective functioning as reflected by the PSCS Valuing and PSI Depression subscales and self-efficacy as indicated by the PSCS Skills and PSI Sense of Competence subscales. The significant correlation between changes on the PSCS Valuing and Skills subscales may further reflect important relationships between parenting satisfaction and sense of efficacy.

While these improvements in parental psychological functioning are noteworthy, it should be pointed out that the present study did not include an "attention" control group; therefore, it is possible that reported improvements were a function of demand characteristics. The stability of improvement into the follow-up period, however, would suggest that bona fide changes had occurred.

Previous studies assessing the impact of parent training on parent and family functioning have yielded positive findings primarily on self-report measures of maternal psychological adjustment, in particular, feelings of depression (Eyberg \& Robinson, 1982; Griest \& Forehand, 1982). The results of the present study support this finding and further suggest that parenting sense of competence is another domain in which parent training may have a positive impact.

Sense of competence and feelings of depression related to parenting may be areas of particular vulnerability when child characteristics are chronic and result in special challenges to parenting (Kazak \& Marvin, 1984). The present results suggest that parent group interventions which provide support, specific knowledge and skills to help parents cope more effectively with their child's particular difficulties may be especially conducive to fostering a sense of parenting competence. The resultant sense of control and mastery may be instrumental in combating depressive symptomatology. Furthermore, for parents of ADDH children, knowledge of the biological basis of their children's problems may also alleviate a sense of culpability related to felt parenting inadequacies. This may further result in improved psychological functioning and self-esteem.

In contrast to the significant improvements on the PSI Parent Domain, change on the Child Domain of the PSI was more attenuated. This may reflect treatment orientation which focused specifically on parent education and skill development and only indirectly targeted child behaviour. Treatment effects for parent-mediated interventions might be more evident on measures related specifically to parent rather than child functioning. In addition, the attenuated effect on the PSI Child Domain may also have reflected parents' appreciation of the relative intransigence of some of their children's problems. The relatively high levels of parental stress on this measure at posttreatment and follow-up would support this view. 
The reductions in stress obtained on the PSI Child Domain were unrelated to changes in the behavioural measures, but were significantly correlated with parents' perceptions that their children were improving. Parents' stress associated with child characteristics may have been directly alleviated as parents worked with others in similar situations and became better educated about the prevalence of the disorder and its biological and chronic nature. These factors may have led parents to also perceive their children as less disordered. As well, parent ratings may have reflected a broader range of child behaviour which were in fact improving and which were not evaluated in the behavioural assessments. It is conceivable that within a clinical range of child behaviour, parents' perceptions of their children may be a better predictor of stress associated with child characteristics than the child's actual behaviour. Other researchers have also found a lack of concordance between observational measures of child behaviour and parental perceptions, especially in the context of parental depression (Forehand, Furey \& McMahon, 1984; Johnston \& Pelham, 1990).

Finally, no significant correlation was found between changes in parent self-report and compliance to treatment. The fact that compliance to treatment was consistently high amongst parents who completed the program may partly account for the lack of significant correlations. Moreover, the compliance measure may have been insensitive to the underlying processes of program participation that relate to parenting stress and sense of competence. Dumas and Albin (1986) obtained similar results in their parent training outcome study.

In conclusion, the results of this study support the notion that group parent training programs can benefit families in a number of ways. Transactional models of family functioning would suggest that alleviating parental stress and improving sense of competence not only provides immediate benefit but also has the potential for preempting dysfunctional recursive cycles that can lead to secondary problems and protracted family pathology.

This research was supported by Ontario Ministry of Health, Health Research Grants 01076 and 01995. Thanks are extended to Marg Parkin for assistance in coding and Janet McLenachan for preparation of the manuscript.

Correspondence concerning this article should be addressed to Susan Pisterman, Psychology Department, Children's Hospital of Eastern Ontario, 401 Smyth Road, Ottawa, Canada, KiH 8L1.

\section{References}

Abidin, R.R. (1983) Parenting Stress Index Clinical Manual Form \#5. University of Virginia.

American Psychiatric Association. (1980). Diagnostic and statistical manual of mental disorders (3rd ed.). Washington, DC: Author. 
Barkley, R.A. (1981). Hyperactive children: $A$ handbook for diagnosis and treatment. New York: Guilford.

Barkley, R.A., \& Cunningham, C.E. (1979). The effects of methylphenidate on the mother-child interactions of hyperactive children. Archives of General Psychiatry, 35, 201-208.

Barkley, R.A., Karlsson, J., Pollard, S., \& Murphy, J.V. (1985). Developmental changes in the mother-child interactions of hyperactive boys: Effects of two dose levels of Ritalin. Journal of Child Psychology and Psychiatry, 25, 705-715.

Belsky, J. (1984). The determinants of parenting: A process model. Child Development, 55, 83-96.

Blechman, E.A., Tryon, A.S., Ruff, M.H., \& McEnroe, M.J. (1989). Family skills training and childhood depression. In C.E. Schaefer \& J.M. Briesmeister (Eds.), Handbook of parent training: Parents as co-therapists for children's behavior problems (pp. 203-222). New York: Wiley.

Conners, C.K. (1989). Manual for Conners' Rating Scales. Toronto, Ontario/North Tonawanda, NY: Multi-Health Systems.

Dodge, K.A. (1990). Developmental psychopathology in children of depressed mothers. Developmental Psychology, 25, 3-6.

Dumas, J.E. (1984). Indiscriminate mothering: Empirical findings and theoretical speculations. Advances in Behavioral Research and Therapy, 5, 13-27.

Dumas, J.E., \& Albin, J.B. (1986). Parent training outcome: Does active parental involvement matter? Behaviour Research and Therapy, 24, 227-230.

Dunn, L.J., \& Dunn, L.M. (1981). Manual for the Peabody Picture Vocabulary Test Revised. Circle Pines, MN: American Guidance Service.

Eyberg, S.M., \& Robinson, E.A. (1982). Parent-child interaction training: Effects on family functioning. Journal of Clinical Child Psychology, 11, 130-137.

Forehand, R., Furey, W.M., \& McMahon, R.J. (1984). The role of maternal distress in a parent training program to modify child non-compliance. Behavioural Psychotherapy, 12, 93-108.

Forehand, R.L., \& McMahon, R.J. (1981). Helping the noncompliant child: A clinician's guide to parent training. New York: Guilford.

Gibaud-Wallston, J., \& Wandersman, L.P. (1978, August). Development and validity of the Parenting Sense of Competence Scale. Paper presented at the meeting of the American Psychological Association, Toronto, Ontario.

Griest, D.L., \& Forehand, R. (1982). How can I get any parent training done with all these other problems going on?: The role of family variables in child behavior therapy. Child \& Family Behavior Therapy, 4, 73-80.

Hammen, C., Burge, D., \& Stansbury, K. (1990). Relationship of mother and child variables to child outcomes in a high-risk sample: A causal modeling analysis. Developmental Psychology, 25, 24-30.

Hanf, C. (1969, April). A two-stage program for modifying maternal controlling during mother-child $(M-C)$ interaction. Paper presented at the Western Psychological Association Meeting, Vancouver, B.C. 
Johnston, C. (1988). A behavioral-family systems approach to assessment: Maternal characteristics associated with externalizing behavior in children. In R.J. Prinz (Ed.), Advances in behavioral assessment of children and families, Vol. 4 (pp. 163-189). Greenwich, CT. JAI Press.

Johnston, C., \& Mash, E.J. (1989). A measure of parenting satisfaction and efficacy. Journal of Clinical Child Psychology, 18, 167-175.

Johnston, C., \& Pelham, Jr., W.E. (1990). Maternal characteristics, ratings of child behavior, and mother-child interactions in families of children with externalizing disorders. Journal of Abnormal Child Psychology, 18, 403-417.

Kazak, A.E., \& Marvin, R.S. (1984). Differences, difficulties and adaptation: Stress and social networks in families with a handicapped child. Family Relations, January, 67-77.

Kendall, P.C., \& Wilcox, L.E. (1979). Self-control in children: Development of a rating scale. Journal of Consulting and Clinical Psychology, 47, 1020-1029.

Kirk, R.E. (1982). Experimental design: Procedures for the behavioral sciences (2nd ed.). Monterey, CA: Brooks/Cole.

Loyd, B.H., \& Abidin, R.R. (1985). Revision of the Parenting Stress Index. Journal of Pediatric Psychology, 10, 169-177.

Mash, E.J., \& Johnston, C. (1983). Parental perceptions of child behavior problems, parenting self-esteem, and mothers reported stress in younger and older hyperactive and normal children. Journal of Consulting and Clinical Psychology, 51, 86-99.

Mash, E.J., \& Johnston, C. (1990). Determinants of parenting stress: Illustrations from families of hyperactive children and families of physically abused children. Journal of Clinical Child Psychology, 19, 313-328.

Minuchin, S. (1974). Families and family therapy. Cambridge, MA: Harvard University Press.

Pelham, W.E., \& Bender, M.E. (1982). Peer relationships in hyperactive children: Description and treatment. In K.D. Gadow \& I. Bialer (Eds.), Advances in learning and behavioral disabilities: $A$ research annual (Vol. 1, pp. 365-436). Greenwich, CT: JAI Press.

Pisterman, S., McGrath, P., Firestone, P., Goodman, J.T., Webster, I., \& Mallory, R. (1989). Outcome of parent mediated treatment of preschoolers with attention deficit disorder with hyperactivity. Journal of Consulting and Clinical Psychology, 57, 628-635.

Pisterman, S., McGrath, P., Firestone, P., Goodman, J.T., Webster, I., Mallory, R., \& Goffin, B. (in press). The role of parent training in the treatment of preschoolers with attention deficit disorder with hyperactivity. American Journal of Orthopsychiatry. 